\title{
Special Issue: Regulation of Corporate Disclosure
}

\author{
Willem F. J. Buijink ${ }^{1,2}$ • Thorsten Sellhorn ${ }^{3}$ Alfred Wagenhofer ${ }^{4}$
}

(C) Schmalenbach-Gesellschaft für Betriebswirtschaft e.V. 2019

\section{Motivation}

The information provided in corporate disclosures is a key contributor to corporate transparency. Firms provide these disclosures either voluntarily - when they consider them privately net-beneficial—or under mandatory requirements—when the information is intended to serve a larger objective. This Special Issue on "Regulation of Corporate Disclosure" focuses on questions related to mandatory disclosure.

Corporate disclosures are financial or non-financial in nature. Financial corporate disclosure regulation is continuously being developed by national (e.g., the U.S. FASB) and supranational standard setters (e.g., the IASB) as well as other policy makers. These bodies are the target of active political lobbying by diverse constituents. Perhaps signaling perceived shortcomings of regulated financial reporting, a growing body of literature documents the rise of non-GAAP or alternative performance measures, by which firms complement their published financial statements (for a recent survey, see, for example, Black et al. 2018). Regulators, including the SEC and ESMA, have seen a need to place restrictions on firms' leeway to pub-

W. F. J. Buijink

W.F.J.Buijink@uvt.nl

$\bowtie$ T. Sellhorn

sellhorn@bwl.lmu.de
A. Wagenhofer
alfred.wagenhofer@uni-graz.at
1 Open University Heerlen, Heerlen, The Netherlands
2 Tilburg University, Tilburg, The Netherlands
3 Ludwig-Maximilians-University Munich, Munich, Germany
4 University of Graz, Graz, Austria 
lish earnings measures that deviate from those defined under applicable financial reporting standards.

Non-financial disclosure regulation has seen even more significant developments in recent years. They culminate in the 2014 Non-Financial Reporting Directive in the European Union (2014/95/EU), which requires additional environmental, social and governance (ESG) disclosures from large public-interest corporations located in the EU. Other large economies, such as China, India, and South Africa, introduced similar non-financial reporting regulations. Unlike the IAS Regulation of 2002 (EC/1606/2002), which affects only publicly traded firms, the scope of the 2014 Directive, which is part of European company law, could "easily" be extended to include a broader set of corporations.

The Call for Papers for this Special Issue expressed an interest of the Schmalenbach Business Review in papers that speak to the effectiveness and efficiency of these and other new developments in disclosure regulation, primarily in terms of intended and unintended consequences. The new regulatory developments are motivated by the traditional objective of corporate disclosure regulation, i.e., increasing the transparency and comparability of corporate activities. However, an important additional, often latent, objective of at least some regulatory actions is behavioral change of corporate decision making through disclosure of specific information. This is known as "real effects" of regulation-instances in which disclosure regulation feeds back into the economic actions of the firms being regulated. In addition to intended real effects, such as firms reducing their carbon footprint as a result of having to report $\mathrm{CO}_{2}$ emissions, real effects can also arise as unintended (or at least unanticipated) side effects of disclosure regulation, such as mandatory quarterly reporting inducing short-termism in managers (e.g., Ernstberger et al. 2017). This Special Issue aims to add to this fascinating and underexplored area of real effects of recent corporate disclosure regulation.

The Special Issue includes three full articles and six invited commentaries. All articles were subject to the standard review process of the Schmalenbach Business Review, of course including the paper coauthored by Thorsten Sellhorn, one of the editors of this Special Issue. The commentaries were reviewed by each of us. We thank all authors and reviewers for their efforts and contributions.

\section{Articles}

The article "Shaping Corporate Actions through Targeted Transparency Regulation: A Framework and Review of Extant Evidence" by Katharina Hombach and Thorsten Sellhorn examines and reviews research in the relatively recent regulatory area of targeted transparency regulation of corporate disclosures. Targeted transparency regulation differs from traditional corporate disclosure regulation in two ways: First, it aims at shaping specific corporate actions vis-à-vis non-investor stakeholders and society at large, rather than promoting price efficiency in financial markets. Second, the mandated disclosures are aimed not only at providing decision-useful information to investors, but also at mobilizing pressure from a broad range of potential users to make corporations "better citizens". The effectiveness and efficiency of this 
targeted transparency regulation is an important empirical question. After laying out the causal mechanisms through which mandated disclosures could shape corporate actions (with a special focus on the role of stakeholder pressure), the authors carefully review the nascent literature on targeted transparency via corporate disclosure regulation.

In "Non-GAAP Reporting and Debt Market Outcomes: Evidence from Regulation G", Felix Thieleman, Tami Dinh, and Helen Kang focus on bond market effects of the disclosure of non-GAAP measures. Complementing other studies that focus on equity-market implications, they study how non-GAAP reporting affects bond spreads and credit ratings. As their instrument, they use the regulation of nonGAAP disclosure by the SEC (Regulation G) in 2002. They find that, after the regulation took effect, non-GAAP earnings disclosures are associated with reduced bond spreads, opposite to the association before 2003. This suggests that the regulation increased the information content of non-GAAP earnings and reduced information asymmetry. In contrast, they find no effect of Regulation $G$ on the association of non-GAAP disclosures with credit ratings. Given the voluntary nature of non-GAAP reporting, identifying the causal effects of Regulation $\mathrm{G}$ on bond-market outcomes is challenging. While the paper presents a solid attempt at causal inference, its main strength lies in rich description of the development of non-GAAP disclosures over time.

In "Mandating the Disclosure of Sustainability Information in Annual Reports-Evidence from the United Kingdom", Katrin Hummel and Peter Rötzel investigate the regulation of non-financial reporting in the context of sustainability disclosure. Specifically, they consider the introduction of Strategic Report and Directors' Report regulations in the United Kingdom in 2013, which mandates disclosures related to greenhouse gas emissions, gender equality, and human rights issues. The authors show that the disclosure mandate enhances two types of disclosures: the mandated key performance indicators and the largely discretionary extent of narrative disclosures. However, reporting incentives appear to mitigate the regulatory effect, with improvements being smaller for firms with higher voluntary reporting incentives. These results suggest that regulation that aims to influence behavior may not achieve its full intended effect on behavior because it can substitute for voluntary disclosure many firms had been providing earlier.

\section{Commentaries}

The six commentaries are written by experts representing different stakeholders of corporate disclosure: preparers, users, standard-setting bodies, advocacy groups, and academics. They provide their views on the following questions: Why is there so much regulatory activity here? Why is there so much interest in recent years in the regulation of non-financial corporate disclosures? What can be expected from these developments? Where should policy makers' priorities lie?

Andreas Barckow from the Accounting Standards Committee of Germany (ASCG) focuses on potential corporate financial and non-financial disclosure regulatory "overload". Detailed financial disclosure requirements may stand in the way 
of corporations wishing to provide individual information to investors. With regard to non-financial reporting regulation, he invites more discussion about the danger of overburdening corporations by imposing targeted transparency requirements that serve broader public policy goals.

Andrew Watchman and Vincent Papa from the European Financial Reporting Advisory Group (EFRAG) argue for a broad review of corporate disclosure regulation-both financial and non-financial. Such a reconsideration would include the "mainstreaming" of environmental, social and governance (ESG) corporate disclosures, with potential "real effects" on capital allocation decisions that could promote sustainable corporate finance. They present EFRAG's new "European Corporate Reporting Lab" as a promising opportunity to improve corporate disclosure.

Hilde Blomme from Accountancy Europe explains Accountancy Europe's "Core \& More" approach to corporate reporting. The "Core" part intends to bring together the most relevant financial and non-financial information about a company. According to their individual information needs, users can then dive into "More" specific and detailed reports that are connected digitally. Collectively, Core \& More reports would satisfy mandatory reporting requirements, with "More" reports including information on, for example, risk management, corporate governance, the financial statements and notes, as well as sustainability information.

Jürgen Wagner from Siemens AG presents a preparer's view on the recent regulatory activities aimed at expanding the reach of corporate reporting beyond the traditional capital market audience. He cautions that this expansion could not only increase the burden of disclosure costs to firms, but simultaneously risks reducing the usefulness of corporate reporting to users.

Franziska Humbert from Oxfam Germany comments on the implementation on non-financial (ESG) reporting in Germany. Using the example of human rights disclosures, she asks whether such mandated disclosures can actually trigger a change in corporate behavior. Being cautiously optimistic, she expects positive effects and is sympathetic to the idea of expanding CSR-type disclosure requirements beyond the group of large, publicly traded firms.

Robert Eccles, of Saïd Business School Oxford University, and Michael Krzus, of Michael Krzus Consulting, present main insights from a study of climate-related disclosures of 15 large oil and gas corporations in the U.S. prior to the 2017 recommendations of the Task Force on Climate-related Financial Disclosures (TCFD). They find substantial voluntary adoption of the recommended disclosures already in 2016, which they argue shows that climate change effects disclosures will not be overly burdensome.

\section{Reflections and Suggestions}

This Special Issue underscores that we are amidst rapid developments in corporate reporting regulation. Whereas opponents of this trend are concerned about undue disclosure costs to preparers (especially induced by targeted transparency regulation) and "information overload" for users, proponents highlight technology as a possible 
way of reducing users' information processing costs or hope for beneficial "real effects" on firms' actions.

Research serves as an input for regulatory action, although perhaps to a lesser extent than academia would wish. In conclusion, we point out where, in our view, the evolution of corporate disclosure regulation has created additional opportunities for research. First, disclosure regulation creates "natural experiments", facilitating research on causal effects of disclosure. Still, causal identification of effects remains challenging, as disclosure regulation is not randomly assigned to subjects, treatment effects can vary, and measuring intended and unintended outcomes is controversial. Several survey papers help keep track of this growing literature, with Huang and Watson (2015), Erkens et al. (2015), Christensen et al. (2019), and Hombach and Sellhorn (this issue) providing examples. Regulatory activity in this area is unlikely to stop soon. For instance, mandated corporate tax disclosures, which are about the social impact of corporations, are firmly on the agenda, certainly in the EU. We hope that the commentaries in this Special Issue, which reflect the views of diverse stakeholder groups, will stimulate more debate and research.

Second, in the Call for Papers we noted that recent years have brought only rare instances of deregulation of corporate disclosure requirements, with quarterly reporting in the EU being one of them. However, we received no submission that investigated deregulation. This is puzzling, as it is unlikely that all financial disclosure regulatory initiatives will be "successful". What explains this "stickiness" of disclosure regulation-lobbying, regulatory capture, self-interested regulators, or other factors-also forms an interesting area of research. Shedding light on these issues will probably require non-archival research approaches, such is interviews or case studies, which could also exploit between-country variation in regulation implementation.

Third, and this broadens the discussion beyond corporate reporting, some of the recent regulation is slowly, but clearly, changing the concept of the corporation as an economic entity (for a recent analysis see Mayer 2018). In fact, changes in the concept of the corporation may be the driver of regulatory action related to corporate disclosures. Why and how the concept of the corporation is changing, and whether this is a desirable development, should be of interest to accounting researchers as well.

Finally and related, we note that there is a history in this area that dates back at least to the 1970s and 1980s. The 1972 Club of Rome report triggered a flurry of interest in the social and environmental impact of corporations that lead to demands for related disclosure regulation. In Europe, this occurred right at the time of the creation of the 4th and 7th EU company law directives (now combined in the 2013 Accounting Directive). In the 1970s and 1980s, this development did not include regulation of non-financial corporate reporting. What prevented it at the time is an interesting question; perhaps there was a reluctance to rethink the notion of the corporation. Milton Friedman's famous intervention in 1970 about the raison d'être of the corporation in a capitalist economy will have affected this. We note that rereading the 1970s and 1980s research literature in this area may also inform current research. The exchange between Benston (1982) and Schreuder and Ramanathan (1984) provides an interesting summary of this earlier research and debate. 


\section{References}

Benston, G. 1982. Accounting and corporate accountability. Accounting, Organizations and Society 7(2):87-105.

Black, D.E., T.E. Christensen, J.T. Ciesielski, and B.C. Whipple. 2018. Non-GAAP reporting: Evidence from academia and current practice. Journal of Business Finance \& Accounting 45(3-4):259-294.

Christensen, H., L. Hail, and C. Leuz. 2019. Economic analysis of widespread adoption of CSR and sustainability reporting standards. Working paper. https://ssrn.com/abstract=3315673.

Erkens, M., L. Paugam, and H. Stolowy. 2015. Non-financial information: state of the art and research perspectives based on a bibliometric study. Comptabilité, Contrôle, Audit 21(3):15-92.

Ernstberger, J., B. Link, M. Stich, and O. Vogler. 2017. The real effects of mandatory quarterly reporting. The Accounting Review 92(5):33-60.

Huang, X., and L. Watson. 2015. Corporate social responsibility research in accounting. Journal of Accounting Literature 34:1-16.

Mayer, C. 2018. Prosperity: better business makes the greater good. Oxford: Oxford University Press.

Schreuder, H., and K. Ramanathan. 1984. Accounting and corporate accountability: an extended comment. Accounting, Organizations and Society 9(3-4):409-415.

Publisher's Note Springer Nature remains neutral with regard to jurisdictional claims in published maps and institutional affiliations. 